\title{
Dipicolinate complexes of main group metals with hydrazinium cation
}

\author{
K SARAVANAN and S GOVINDARAJAN* \\ Department of Chemistry, Bharathiar University, Coimbatore 641 046, India \\ e-mail: drsgovind@vsnl.net
}

MS received 21 June 2001; revised 29 October 2001

\begin{abstract}
Some new coordination complexes of hydrazinium main group metal dipicolinate hydrates of formulae $\left(\mathrm{N}_{2} \mathrm{H}_{5}\right)_{2} \mathrm{M}(\mathrm{dip})_{2} \cdot n \mathrm{H}_{2} \mathrm{O}$ (where, $\mathrm{M}=\mathrm{Ca}, \mathrm{Sr}, \mathrm{Ba}$ or $\mathrm{Pb}$ and $n=0,2,4$ and 3 respectively and dip = dipicolinate), $\mathrm{N}_{2} \mathrm{H}_{5} \mathrm{Bi}(\operatorname{dip})_{2} .3 \mathrm{H}_{2} \mathrm{O}$ and $\left(\mathrm{N}_{2} \mathrm{H}_{5}\right)_{3} \mathrm{Bi}(\mathrm{dip})_{3} .4 \mathrm{H}_{2} \mathrm{O}$ have been prepared and characterized by physico-chemical techniques. The infrared spectra of the complexes reveal the presence of tridentate dipicolinate dianions and non-coordinating hydrazinium cations. Conductance measurements show that the mono, di and trihydrazinium complexes behave as $1: 1$, $2: 1$ and $3: 1$ electrolytes respectively, in aqueous solution. Thermal decomposition studies show that these compounds lose water followed by endothermic decomposition of hydrazine to give respective metal hydrogendipicolinate intermediates, which further decompose exothermically to the final product of either metal carbonates $(\mathrm{Ca}, \mathrm{Sr}, \mathrm{Ba}$ and $\mathrm{Pb})$ or metal oxycarbonates $(\mathrm{Bi})$. The coordination numbers around the metal ions differ from compound to compound. The various coordination numbers exhibited by these metals are six $(\mathrm{Ca})$, seven $(\mathrm{Ba})$, eight $(\mathrm{Sr})$ and nine $(\mathrm{Pb}$ and $\mathrm{Bi})$. In all the complexes the above coordination number is attained by tridentate dipicolinate dianions and water molecules. The X-ray diffraction patterns of these compounds differ from one another suggesting that they are not isomorphous.
\end{abstract}

Keywords. Hydrazinium; dipicolinate; main group metals; thermal analysis.

\section{Introduction}

The capacity of pyridine carboxylic acids to act as ligand is an important property, relevant in several areas of chemistry and in other sciences. The pyridine carboxylic acids, which have been by far most studied as ligands, are picolinic, nicotinic, isonicotinic, quinolinic, lutidinic, isocinchomeronic, dipicolinic, cinchomeronic and dinicotinic acid. Among these acids, the coordination chemistry of dipicolinic acid (pyridine-2,6-dicarboxylic acid, $\mathrm{H}_{2}$ dip) has attracted great attention for long time and significant progress has been made in understanding the structure of its complexes, both in solution ${ }^{1}$ and in the solid state ${ }^{2}$.

The interest in this ligand seems to centre on the versatile and unpredictable manner in which it co-ordinates to a variety of metals. The different coordination modes for the dipicolinate dianion are shown in figure 1. Among these modes, the rigid tridentate coordination of this flat chelate ligand (figure 1a) is found for many bivalent or trivalent transition metals ${ }^{3,4}$. There are, however, a few examples of other coordination modes of

\footnotetext{
*For correspondence
} 
(a)

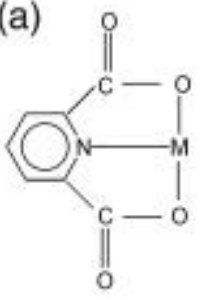

(c)

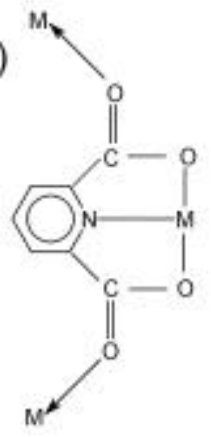

(b)<smiles></smiles>

(d)<smiles></smiles>

Figure 1. Coordination modes for the dipicolinate dianion.

this ligand such as bridging of two metal atoms (figure $1 \mathrm{~b})^{5}$, polymerization of chelate complexes by coordination of the carbonyl atom (figure $1 \mathrm{c})^{6}$ and bidentate $\mathrm{N}-\mathrm{O}$ coordination (figure $1 \mathrm{~d})^{7}$.

Based upon the coordination number of six to nine, commonly adopted by many main group metals, and the ability of $\operatorname{dip}^{2-}$ to function as a tridentate ligand, we expect to find anionic complexes of the type $\left[\mathrm{M}(\mathrm{dip})_{2}\right]^{x-}(x=1$ or 2$)$ and $\left[\mathrm{M}(\mathrm{dip})_{3}\right]^{x_{-}}(x=3$ or 4$)$. A number of such complexes has been reported for transition metal ions, lanthanides and actinides, examples being $\mathrm{Na}\left[\mathrm{M}(\operatorname{dip})_{2}\right] \cdot 2 \mathrm{H}_{2} \mathrm{O} \quad(\mathrm{M}=\mathrm{Ru}, \mathrm{Ir})^{6}, \mathrm{Na}\left[\mathrm{Cr}(\operatorname{dip})_{2}\right] \cdot 1 \cdot 5 \mathrm{H}_{2} \mathrm{O}^{8}$, $\left(\mathrm{N}\left(\mathrm{C}_{3} \mathrm{H}_{7}\right)_{4}\right)_{2}\left[\mathrm{Fe}(\operatorname{dip})_{2}\right] \cdot 7 \cdot 25 \mathrm{H}_{2} \mathrm{O}^{9}, \quad \mathrm{Na}\left[\mathrm{Fe}(\operatorname{dip})_{2}\right] \cdot 2 \mathrm{H}_{2} \mathrm{O}^{9}, \quad \mathrm{Na}_{2}\left[\mathrm{M}(\mathrm{dip})_{2}\right] \cdot n \mathrm{H}_{2} \mathrm{O}^{10} \quad(\mathrm{M}=\mathrm{Mn}$, $\mathrm{Co}, \mathrm{Ni}, \mathrm{Cu}$ or $\mathrm{Zn} ; n=2$ or 3 ), some $\mathrm{Nd}$ and $\mathrm{Yb}$ complexes of the type $\mathrm{Na}_{3}\left[\mathrm{M}(\operatorname{dip})_{3}\right] \cdot n \mathrm{H}_{2} \mathrm{O}^{11}$ and few actinide complexes $\left(\mathrm{Ph}_{4} \mathrm{As}\right)_{2}\left[\mathrm{U}(\mathrm{dip})_{3}\right] \cdot 3 \mathrm{H}_{2} \mathrm{O}^{12}$ and $\left(\mathrm{Ph}_{4} \mathrm{As}\right)_{2}\left[\mathrm{UO}_{2}(\mathrm{dip})_{2}\right] \cdot 6 \mathrm{H}_{2} \mathrm{O}^{13}$. Apparently similar anionic complexes of main group metal ions have not been studied. This prompted us to study the dipicolinate complexes of main group metals with hydrazinium cation. We have chosen hydrazinium ion $\left(\mathrm{N}_{2} \mathrm{H}_{5}{ }^{+}\right)$as cation due to its intersting versatile nature, i.e., it can either act as a coordinating ligand to the metal ${ }^{14,15}$ or as an ionic ${ }^{16}$ species like $\mathrm{NH}_{4}{ }^{+}$counterion.

The complexes have been isolated in the solid state and structures have been assigned tentatively on the basis of their analytical, spectral, powder X-ray diffraction and thermal studies. The results of these studies are given in this paper.

\section{Experimental}

All the chemicals used were AnalaR grade and the solvents were freshly distilled before use. Hydrazine hydrate of $99-100 \%$ purity was used in all the reactions. 
2.1 Preparation of $\left(\mathrm{N}_{2} \mathrm{H}_{5}\right)_{2} \mathrm{Ca}(\text { dip })_{2}$ and $\left(\mathrm{N}_{2} \mathrm{H}_{5}\right)_{2} \mathrm{Sr}(\text { dip })_{2} .2 \mathrm{H}_{2} \mathrm{O}$

The respective metal nitrates $\left[\mathrm{Ca}\left(\mathrm{NO}_{3}\right)_{2} .4 \mathrm{H}_{2} \mathrm{O}, 0.4724 \mathrm{~g}, 0.002 \mathrm{~mol}\right.$ and $\mathrm{Sr}\left(\mathrm{NO}_{3}\right)_{2}$, $0.4232 \mathrm{~g}, 0.002 \mathrm{~mol}]$ dissolved in water $(50 \mathrm{ml})$ was added solid dipicolinic acid $(0.6684 \mathrm{~g}, 0.004 \mathrm{~mol})$. The resulting mixture was heated over a waterbath until the acid dissolved and a clear solution formed. To the clear solution, in the hot condition, $100 \%$ hydrazine hydrate $(0.35 \mathrm{ml}, 0.007 \mathrm{~mol})$ was added with stirring and the $p \mathrm{H}$ of the solution was adjusted to 6 by adding a few drops of $10 \%$ hydrazine hydrate. This solution was concentrated to a $20 \mathrm{ml}$ volume over a waterbath and then kept for crystallisation at room temperature. After four days, the crystalline solids deposited were collected by filtration and washed with ice-cold water-alcohol (1:1) mixture and air-dried.

\subsection{Preparation of $\left(\mathrm{N}_{2} \mathrm{H}_{5}\right)_{2} \mathrm{Ba}(\text { dip })_{2} .4 \mathrm{H}_{2} \mathrm{O}$}

Solid dipicolinc acid $(0.6684 \mathrm{~g}, 0.004 \mathrm{~mol})$ was added to a $50 \mathrm{ml}$ of water containing $\mathrm{Ba}\left(\mathrm{NO}_{3}\right)_{2}(0.5228 \mathrm{~g}, 0.002 \mathrm{~mol})$ at room temperature. On heating, the acid dissolved and the solution became turbid. To this turbid solution, in hot condition, $100 \%$ hydrazine hydrate $(0.35 \mathrm{ml}, 0.007 \mathrm{~mol})$ was added with stirring. Few drops of $10 \% \mathrm{~N}_{2} \mathrm{H}_{4}$ was added until all solids had dissolved and the solution $p \mathrm{H}$ was 6 . The resulting solution was heated on a waterbath for $30 \mathrm{~min}$ and then kept for crystallisation at room temperature. White powdered solid formed after $24 \mathrm{~h}$ was filtered out and the filtrate was reduced to $25 \mathrm{ml}$ volume and left at room temperature for 4 days. The crystalline complex formed was filtered off and washed with ice-cold water-alcohol (1:1) mixture and air-dried.

\subsection{Preparation of $\left(\mathrm{N}_{2} \mathrm{H}_{5}\right)_{2} \mathrm{~Pb}(\text { dip })_{2} .3 \mathrm{H}_{2} \mathrm{O}$}

Solid dipicolinic acid $(0.6684 \mathrm{~g}, 0.004 \mathrm{~mol})$ was added to a hot solution of $\mathrm{Pb}\left(\mathrm{NO}_{3}\right)_{2}$ $(0.6624 \mathrm{~g}, 0.002 \mathrm{~mol})$ in water $(75 \mathrm{ml})$. The acid dissolved with a formation of white precipitate. To this, in hot condition, $100 \%$ hydrazine hydrate $(0.35 \mathrm{ml}, 0.007 \mathrm{~mol})$ was added with constant stirring. The $p \mathrm{H}$ of the mixture was adjusted to 6 by careful addition of a few drops of $10 \%$ hydrazine hydrate. On the addition of base, a large portion of the precipitate dissolved and was heated on a waterbath about an hour, in order to solubilise maximum amount of precipitate. After an hour of heating, the slight insoluble present was filtered off and the filtrate was reduced to $25 \mathrm{ml}$ volume by heating on waterbath and was kept for crystallisation at room temperature. The white crystalline complex formation started after two days and the crystallisation was allowed to continue up to 5 days. After 5 days the complex obtained was filtered off and washed with ice-cold water-alcohol $(1: 1)$ mixture and air dried. The shiny crystals effloresced the water molecules and became opaque within two days. All the studies were carried out on opaque crystals.

\subsection{Preparation of $\mathrm{N}_{2} \mathrm{H}_{5} \mathrm{Bi}(\text { dip })_{2} \cdot 3 \mathrm{H}_{2} \mathrm{O}$}

$\mathrm{Bi}\left(\mathrm{NO}_{3}\right)_{3} .5 \mathrm{H}_{2} \mathrm{O} \quad(0.98 \mathrm{~g}, 0.002 \mathrm{~mol})$ and dipicolinic acid $(0.6684 \mathrm{~g}, 0.004 \mathrm{~mol})$ were mixed in $100 \mathrm{ml}$ water and on heating both dissolved and a turbid solution was formed. To this turbid solution in hot condition $100 \%$ hydrazine hydrate $(0.35 \mathrm{ml}, 0.007 \mathrm{~mol})$ was added with stirring, until a clear solution was obtained. Few drops of $10 \% \mathrm{~N}_{2} \mathrm{H}_{4} \cdot \mathrm{H}_{2} \mathrm{O}$ was added until the $p \mathrm{H}$ of the solution had a value $\approx 6$. The solution was heated for $30 \mathrm{~min}$ and the negligible amount of solid present was filtered out and the filtrate was reduced to 
$30 \mathrm{ml}$ volume by heating on waterbath and then kept for crystallisation at room temperature. White solid formation started on the second day onwards and was filtered after four days and, washed and dried as before.

\subsection{Preparation of $\left(\mathrm{N}_{2} \mathrm{H}_{5}\right)_{3} \mathrm{Bi}(\text { dip })_{3} \cdot 4 \mathrm{H}_{2} \mathrm{O}$}

$\mathrm{Bi}\left(\mathrm{NO}_{3}\right)_{3} .5 \mathrm{H}_{2} \mathrm{O}(0.98 \mathrm{~g}, 0.002 \mathrm{~mol})$ and dipicolinic acid $(1 \mathrm{~g}, 0.006 \mathrm{~mol})$ were mixed in $100 \mathrm{ml}$ of water and on heating both dissolved and turbid solution formed. To this turbid solution in hot condition $100 \%$ hyrdrazine hydrate $(0.6 \mathrm{ml}, 0.012 \mathrm{~mol})$ was added with stirring and the solution became clear with $p \mathrm{H}=6$. The resulting clear solution was concentrated to a $30 \mathrm{ml}$ volume on a waterbath, filtered and then kept for crystallisation at room temperature. The hexagonal-shaped crystals formed, after five days, were collected by filteration and washed with ice-cold water-alcohol $(1: 1)$ mixture and air dried. The shiny crystals effloresced the water molecules and became opaque within two days and the studies were carried out on opaque crystals.

\subsection{Analyses}

The metal content in all the complexes was determined by EDTA complexometric titration, after decomposing a known weight of the sample with concentrated nitric acid. The hydrazine content was determined volumetrically using $0.025 \mathrm{M} \quad \mathrm{KIO}_{3}$ solution under Andrews' conditions.

\subsection{Physicochemical studies}

The molar conductances of the complexes in $0.001 \mathrm{M}$ solutions, in water, were measured using Elico CM183 EC-TDS analyser. The IR spectra of the solid samples in the range $4000-400 \mathrm{~cm}^{-1}$ were recorded on a Shimadzu FTIR 8000 spectrophotometer using $\mathrm{KBr}$ pellets. Simultaneous TG-DTA experiments were carried out using STA 1500 systems. The heating rate employed was $10^{\circ} \mathrm{C} \mathrm{min}^{-1}$ in air. About $10 \mathrm{mg}$ of the sample was used for each experiment. The X-ray powder diffraction patterns of the samples were obtained using a JEOL JDX 8030 X-ray diffractometer using $\mathrm{CuK}_{\alpha}$ radiation with nickel filter.

\section{Results and discussion}

The reaction of metal nitrates (1 part) with dipicolinic acid ( 2 or 3 parts) and hydrazine hydrate (3.5 or 6 parts) yielded the hydrazinium metal dipicolinate hydrates of formula $\left(\mathrm{N}_{2} \mathrm{H}_{5}\right)_{2} \mathrm{M}(\text { dip })_{2} \cdot n \mathrm{H}_{2} \mathrm{O}$, where $n=0$ for $\mathrm{M}=\mathrm{Ca}, n=2$ for $\mathrm{M}=\mathrm{Sr}, n=4$ for $\mathrm{M}=\mathrm{Ba}$ and $n=3$ for $\mathrm{M}=\mathrm{Pb}, \mathrm{N}_{2} \mathrm{H}_{5} \mathrm{Bi}(\operatorname{dip})_{2} 3 \mathrm{H}_{2} \mathrm{O}$ and $\left(\mathrm{N}_{2} \mathrm{H}_{5}\right)_{3} \mathrm{M}(\mathrm{dip})_{3} 4 \mathrm{H}_{2} \mathrm{O}$. The chemical analyses (table 1) of these complexes conform to the desired composition.

\subsection{Molar conductance}

The molar conductances of $0.001 \mathrm{M}$ aqueous solutions of the complexes are given in table 1. The calcium, strontium, barium and lead complexes show conductance value in the range $231-249 \mathrm{~cm}^{2}$ mho mol${ }^{-1}$, indicating their $2: 1$ electrolytic nature, for which $\Lambda_{M}$ is expected to be in the range 230-270 $\mathrm{cm}^{2}$ mho mol${ }^{-117}$. The monohydrazinium bismuth complex shows conductance value close to $1: 1$ electrolyte (e.g., 
Table 1. Analytical and molar conductance data.

\begin{tabular}{|c|c|c|c|c|c|c|}
\hline \multirow[b]{2}{*}{ Compound } & \multirow[b]{2}{*}{ Colour } & \multicolumn{2}{|c|}{ Hydrazine (\%) } & \multicolumn{2}{|c|}{ Metal (\%) } & \multirow{2}{*}{$\begin{array}{l}\text { Molar conductance } \\
\quad\left(\mathrm{cm}^{2} \mathrm{mho} \mathrm{mol}^{-1}\right)\end{array}$} \\
\hline & & Obs. & Calcd. & Obs. & Calcd. & \\
\hline$\left(\mathrm{N}_{2} \mathrm{H}_{5}\right)_{2} \mathrm{Ca}(\mathrm{dip})_{2}$ & White & $14 \cdot 10$ & $14 \cdot 67$ & $9 \cdot 70$ & $9 \cdot 19$ & 231 \\
\hline$\left(\mathrm{N}_{2} \mathrm{H}_{5}\right)_{2} \mathrm{Sr}(\mathrm{dip})_{2} \cdot 2 \mathrm{H}_{2} \mathrm{O}$ & White & $12 \cdot 20$ & $12 \cdot 31$ & $17 \cdot 20$ & $16 \cdot 85$ & 237 \\
\hline$\left(\mathrm{N}_{2} \mathrm{H}_{5}\right)_{2} \mathrm{Ba}(\mathrm{dip})_{2} \cdot 4 \mathrm{H}_{2} \mathrm{O}$ & White & $10 \cdot 30$ & $10 \cdot 57$ & 21.90 & $22 \cdot 68$ & 249 \\
\hline$\left(\mathrm{N}_{2} \mathrm{H}_{5}\right)_{2} \mathrm{~Pb}(\mathrm{dip})_{2} \cdot 3 \mathrm{H}_{2} \mathrm{O}$ & White & $9 \cdot 70$ & $9 \cdot 73$ & $32 \cdot 40$ & 31.52 & 240 \\
\hline $\mathrm{N}_{2} \mathrm{H}_{5} \mathrm{Bi}(\operatorname{dip})_{2} .3 \mathrm{H}_{2} \mathrm{O}$ & White & $5 \cdot 10$ & $5 \cdot 11$ & 33.90 & $33 \cdot 37$ & 126 \\
\hline$\left(\mathrm{N}_{2} \mathrm{H}_{5}\right)_{3} \mathrm{Bi}(\operatorname{dip})_{3} \cdot 4 \mathrm{H}_{2} \mathrm{O}$ & White & $10 \cdot 50$ & $10 \cdot 59$ & $22 \cdot 70$ & $23 \cdot 05$ & 372 \\
\hline
\end{tabular}

Table 2. Infrared spectral data $\left(\mathrm{cm}^{-1}\right)$.

\begin{tabular}{|c|c|c|c|c|c|c|c|}
\hline Compound & $v(\mathrm{O}-\mathrm{H})$ & $v(\mathrm{~N}-\mathrm{H})$ & $\begin{array}{c}\text { Ring } \\
\text { vibration }\end{array}$ & $\begin{array}{c}v_{\text {asy }} \\
\left(\mathrm{COO}^{-}\right)\end{array}$ & $\begin{array}{c}v_{\mathrm{sy}} \\
\left(\mathrm{COO}^{-}\right)\end{array}$ & $\begin{array}{c}\Delta v\left[v_{\text {asy }}\right. \\
\left(\mathrm{COO}^{-}\right)^{-} \\
\left.v_{\mathrm{sy}}\left(\mathrm{COO}^{-}\right)\right]\end{array}$ & $v(\mathrm{~N}-\mathrm{N})$ \\
\hline$\left(\mathrm{N}_{2} \mathrm{H}_{5}\right)_{2} \mathrm{Ca}(\mathrm{dip})_{2}$ & - & $\begin{array}{l}3320 \\
3190\end{array}$ & 1616 & 1586 & 1384 & 202 & 957 \\
\hline$\left(\mathrm{N}_{2} \mathrm{H}_{5}\right)_{2} \mathrm{Sr}(\mathrm{dip})_{2} \cdot 2 \mathrm{H}_{2} \mathrm{O}$ & 3450 & $\begin{array}{l}3090 \\
3285 \\
3090\end{array}$ & 1621 & 1603 & 1381 & 222 & 967 \\
\hline$\left(\mathrm{N}_{2} \mathrm{H}_{5}\right)_{2} \mathrm{Ba}(\mathrm{dip})_{2} \cdot 4 \mathrm{H}_{2} \mathrm{O}$ & 3446 & 2982 & 1629 & 1602 & 1374 & 228 & 966 \\
\hline$\left(\mathrm{N}_{2} \mathrm{H}_{5}\right)_{2} \mathrm{~Pb}(\mathrm{dip})_{2} \cdot 3 \mathrm{H}_{2} \mathrm{O}$ & 3325 & $\begin{array}{l}3075 \\
2997\end{array}$ & 1622 & 1565 & 1366 & 199 & 951 \\
\hline $\mathrm{N}_{2} \mathrm{H}_{5} \mathrm{Bi}(\operatorname{dip})_{2} \cdot 3 \mathrm{H}_{2} \mathrm{O}$ & $\begin{array}{l}3412 \\
3325\end{array}$ & 3083 & 1641 & 1583 & 1374 & 209 & 947 \\
\hline$\left(\mathrm{N}_{2} \mathrm{H}_{5}\right)_{3} \mathrm{Bi}(\mathrm{dip})_{3} \cdot 4 \mathrm{H}_{2} \mathrm{O}$ & $\begin{array}{l}3425 \\
3321\end{array}$ & $\begin{array}{l}3200 \\
3088 \\
2931\end{array}$ & 1622 & 1567 & 1382 & 185 & 957 \\
\hline
\end{tabular}

$\mathrm{NaCl}-120 \mathrm{~cm}^{2}$ mho $\mathrm{mol}^{-1}$ ), whereas trihydrazinium bismuth complex shows conductance value (372) close to $3: 1$ electrolyte $^{17}$.

\subsection{Infrared spectra}

The infrared spectral data of all the complexes are summarised in table 2 and are assigned on the basis of earlier studies ${ }^{18}$. The infrared spectra of calcium and monohydrazinium bismuth complexes are given in figures 2 and 3, as typical examples. Except calcium, all the compounds exhibit strong bands in the range $3450-3325 \mathrm{~cm}^{-1}$ due to $\mathrm{O}-\mathrm{H}$ stretching, confirming the presence of water molecule in the compounds. All the compounds show moderately strong bands in the region $3320-2930 \mathrm{~cm}^{-1}$ due to $\mathrm{N}-\mathrm{H}$ stretching. The bands in the region $1640-1615 \mathrm{~cm}^{-1}$ correspond to the ring vibration. The increase in the value of ring vibration (about $20 \mathrm{~cm}^{-1}$ ) from the free ligand shows the coordination of ring nitrogen to the metal ${ }^{2}$. The asymmetric and symmetric stretching frequencies of carboxylate ions are seen in the ranges $1603-1560$ and $1384-1360 \mathrm{~cm}^{-1}$, respectively with a $\left(\boldsymbol{V}_{\text {asy }}-\boldsymbol{V}_{\text {sym }}\right)$ separation of $228-185 \mathrm{~cm}^{-1}$, indicating the monodentate linkage of both the carboxylate groups in the dianion. The $\mathrm{N}-\mathrm{N}$ stretching frequency of the $\mathrm{N}_{2} \mathrm{H}_{5}{ }^{+}$ion in these complexes, appear in the range $967-947 \mathrm{~cm}^{-1}$ which is in accordance with the noncoordinated $\mathrm{N}_{2} \mathrm{H}_{5}{ }^{+}$ion ${ }^{18}$. 


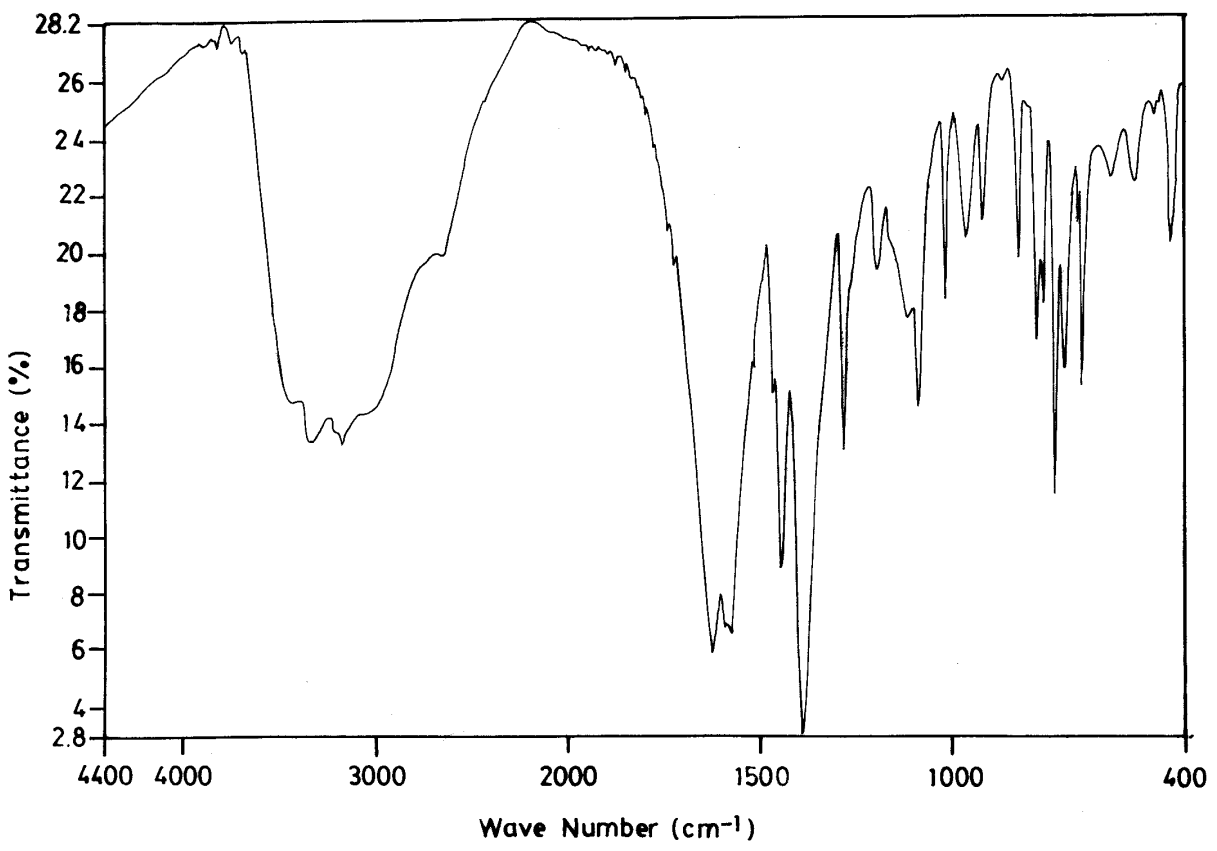

Figure 2. Infrared spectrum of $\left(\mathrm{N}_{2} \mathrm{H}_{5}\right)_{2} \mathrm{Ca}(\mathrm{dip})_{2}$.

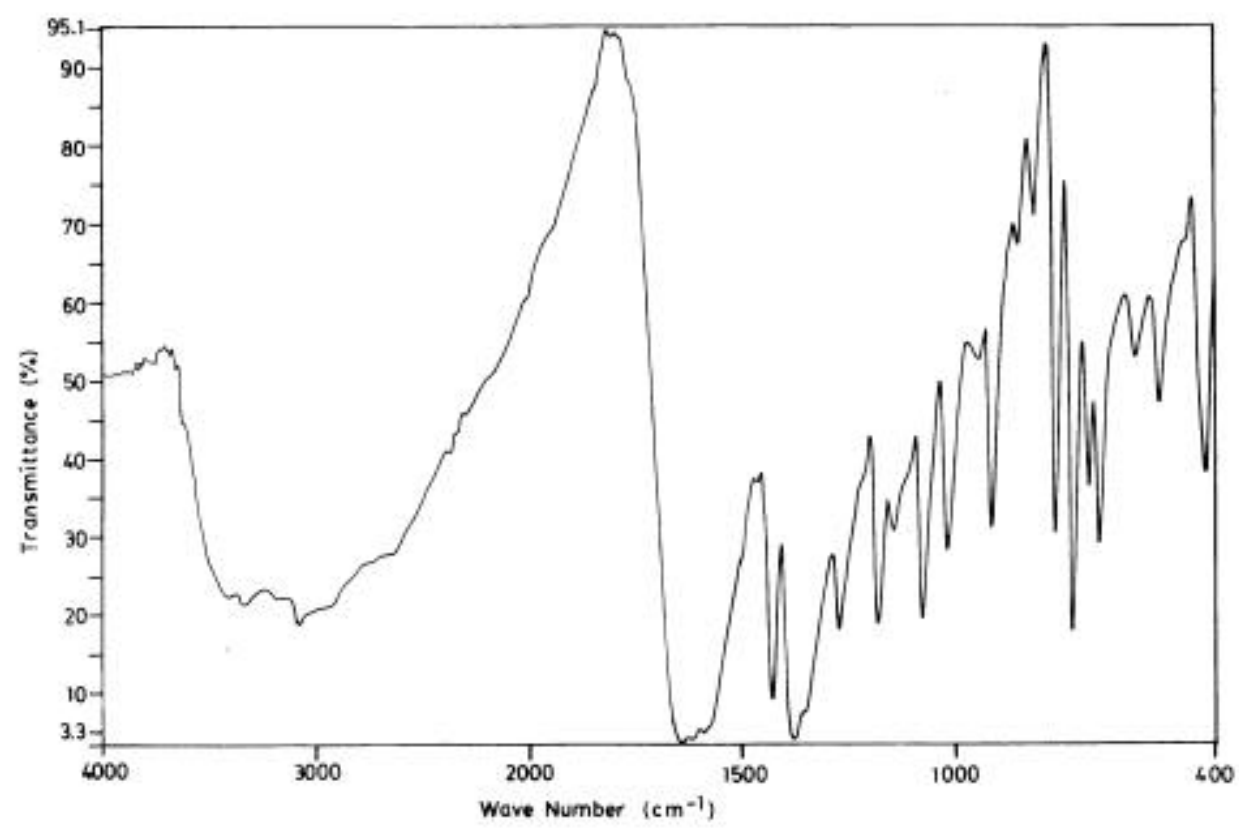

Figure 3. Infrared spectrum of $\mathrm{N}_{2} \mathrm{H}_{5} \mathrm{Bi}(\mathrm{dip})_{2} .3 \mathrm{H}_{2} \mathrm{O}$. 
Table 3. Thermal data.

\begin{tabular}{|c|c|c|c|c|c|}
\hline \multirow[b]{3}{*}{ Compound } & \multirow{3}{*}{$\begin{array}{l}\text { DTA peak } \\
\text { temp. }\left({ }^{\circ} \mathrm{C}\right)\end{array}$} & \multicolumn{3}{|c|}{ Thermogravimetry } & \multirow{3}{*}{$\begin{array}{l}\text { Intermediates/ } \\
\text { end products }\end{array}$} \\
\hline & & \multirow{2}{*}{$\begin{array}{l}\text { Temp. } \\
\text { range }\left({ }^{\circ} \mathrm{C}\right)\end{array}$} & \multicolumn{2}{|c|}{ Mass loss (\%) } & \\
\hline & & & Obs. & Cald. & \\
\hline \multirow[t]{6}{*}{$\left(\mathrm{N}_{2} \mathrm{H}_{5}\right)_{2} \mathrm{Ca}(\mathrm{dip})_{2}$} & $113(+)$ & $40-195$ & $7 \cdot 50$ & $7 \cdot 33$ & $\mathrm{~N}_{2} \mathrm{H}_{5}[\mathrm{Ca}(\mathrm{Hdip})(\operatorname{dip})]$ \\
\hline & $216(+)$ & $195-230$ & $14 \cdot 50$ & $14 \cdot 67$ & $\mathrm{Ca}(\mathrm{Hdip})_{2}$ \\
\hline & $289(-)$ & & & & \\
\hline & $447(-)$ & $230-540$ & $54 \cdot 00$ & $52 \cdot 97$ & $\mathrm{Ca}(\mathrm{dip})$ \\
\hline & $537(-)$ & & & & \\
\hline & $593(-)$ & $540-625$ & $73 \cdot 50$ & $77 \cdot 06$ & $\mathrm{CaCO}_{3}$ \\
\hline \multirow[t]{3}{*}{$\left(\mathrm{N}_{2} \mathrm{H}_{5}\right)_{2} \mathrm{Sr}(\mathrm{dip})_{2} \cdot 2 \mathrm{H}_{2} \mathrm{O}$} & $190(+)$ & $85-195$ & $6 \cdot 80$ & $6 \cdot 92$ & $\left(\mathrm{~N}_{2} \mathrm{H}_{5}\right)_{2}\left[\mathrm{Sr}(\operatorname{dip})_{2}\right]$ \\
\hline & $270(+)$ & $215-270$ & $20 \cdot 60$ & $19 \cdot 24$ & $\operatorname{Sr}(\operatorname{Hdip})_{2}$ \\
\hline & $\begin{array}{l}520(-) \\
555(-)\end{array}$ & $271-560$ & $71 \cdot 50$ & $71 \cdot 60$ & $\mathrm{SrCO}_{3}$ \\
\hline \multirow[t]{5}{*}{$\left(\mathrm{N}_{2} \mathrm{H}_{5}\right)_{2} \mathrm{Ba}(\mathrm{dip})_{2} \cdot 4 \mathrm{H}_{2} \mathrm{O}$} & $67(+)$ & $45-80$ & $8 \cdot 50$ & 8.90 & $\left(\mathrm{~N}_{2} \mathrm{H}_{5}\right)_{2}\left[\mathrm{Ba}(\operatorname{dip})_{2}\left(\mathrm{H}_{2} \mathrm{O}\right)\right]$ \\
\hline & $142(+)$ & $80-145$ & $12 \cdot 90$ & $11 \cdot 89$ & $\left(\mathrm{~N}_{2} \mathrm{H}_{5}\right)_{2}\left[\mathrm{Ba}(\mathrm{dip})_{2}\right]$ \\
\hline & $221(+)$ & $145-245$ & $22 \cdot 40$ & $22 \cdot 46$ & $\mathrm{Ba}(\text { Hdip })_{2}$ \\
\hline & $\begin{array}{l}360(-) \\
490(-)\end{array}$ & $245-520$ & $50 \cdot 00$ & $50 \cdot 06$ & $\mathrm{Ba}(\mathrm{dip})$ \\
\hline & $565(-)$ & $520-570$ & $67 \cdot 50$ & $67 \cdot 41$ & $\mathrm{BaCO}_{3}$ \\
\hline \multirow[t]{3}{*}{$\left(\mathrm{N}_{2} \mathrm{H}_{5}\right)_{2} \mathrm{~Pb}(\operatorname{dip})_{2} \cdot 3 \mathrm{H}_{2} \mathrm{O}$} & $220(+)$ & $100-245$ & $8 \cdot 00$ & $8 \cdot 21$ & $\left(\mathrm{~N}_{2} \mathrm{H}_{5}\right)_{2}\left[\mathrm{~Pb}(\mathrm{dip})_{2}\right]$ \\
\hline & $385(+)$ & $245-390$ & $30 \cdot 00$ & $31 \cdot 34$ & $\mathrm{~Pb}(\text { pic })_{2}$ \\
\hline & $\left.\begin{array}{l}452(-) \\
496(-) s h\end{array}\right\}$ & $390-515$ & $58 \cdot 00$ & $59 \cdot 36$ & $\mathrm{PbCO}_{3}$ \\
\hline \multirow[t]{3}{*}{$\mathrm{N}_{2} \mathrm{H}_{5} \mathrm{Bi}(\mathrm{dip})_{2} \cdot 3 \mathrm{H}_{2} \mathrm{O}$} & $270(+)$ & $75-315$ & $14 \cdot 00$ & $13 \cdot 73$ & Bi(Hdip)(dip) \\
\hline & $415(-)$ & & & & \\
\hline & $\begin{array}{l}441(-) \\
479(-) s h\end{array}$ & $315-480$ & $58 \cdot 00$ & $59 \cdot 28$ & $\mathrm{Bi}_{2} \mathrm{O}_{2} \mathrm{CO}_{3}$ \\
\hline \multirow[t]{3}{*}{$\left(\mathrm{N}_{2} \mathrm{H}_{5}\right)_{3} \mathrm{Bi}(\mathrm{dip})_{3} \cdot 4 \mathrm{H}_{2} \mathrm{O}$} & $73(+)$ & $30-105$ & $8 \cdot 00$ & $8 \cdot 23$ & $\left(\mathrm{~N}_{2} \mathrm{H}_{5}\right)_{3}\left[\mathrm{Bi}(\mathrm{dip})_{3}\right]$ \\
\hline & $\begin{array}{l}262(+) \\
397(-)\end{array}$ & $105-300$ & $38 \cdot 00$ & $38 \cdot 28$ & $\mathrm{Bi}(\mathrm{Hdip})(\mathrm{dip})$ \\
\hline & $\begin{array}{l}426(-) \\
454(-)\end{array}$ & $300-490$ & $69 \cdot 10$ & $70 \cdot 87$ & $\mathrm{Bi}_{2} \mathrm{O}_{2} \mathrm{CO}_{3}$ \\
\hline
\end{tabular}

(+): Endotherm; (-): exotherm, sh: shoulder

\subsection{Thermal analysis}

The thermal data of the complexes are listed in table 3. The compositions of the intermediates and the final products are those, which fit with the observed mass losses in TG. Thermogravimetric results are in good agreement with the DTA data. The simultaneous TG-DTA traces of calcium, barium and monohydrazinium bismuth complexes are shown in figures 4,5 and 6, respectively, as representative examples.

3.3a $\left(\mathrm{N}_{2} \mathrm{H}_{5}\right)_{2} \mathrm{Ca}(\mathrm{dip})_{2}$ : The TG of the compound shows four steps of decomposition in accordance with DTA showing two endotherms and two exotherms. The first endotherm 


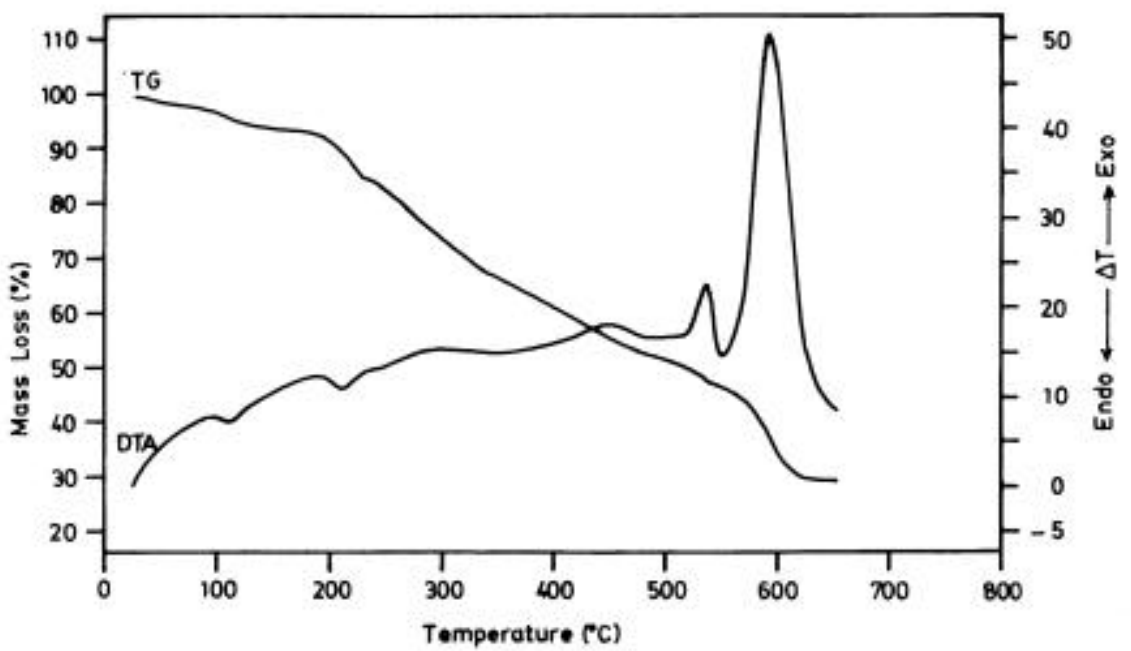

Figure 4. Simultaneous TG-DTA curves of $\left(\mathrm{N}_{2} \mathrm{H}_{5}\right)_{2} \mathrm{Ca}(\mathrm{dip})_{2}$.

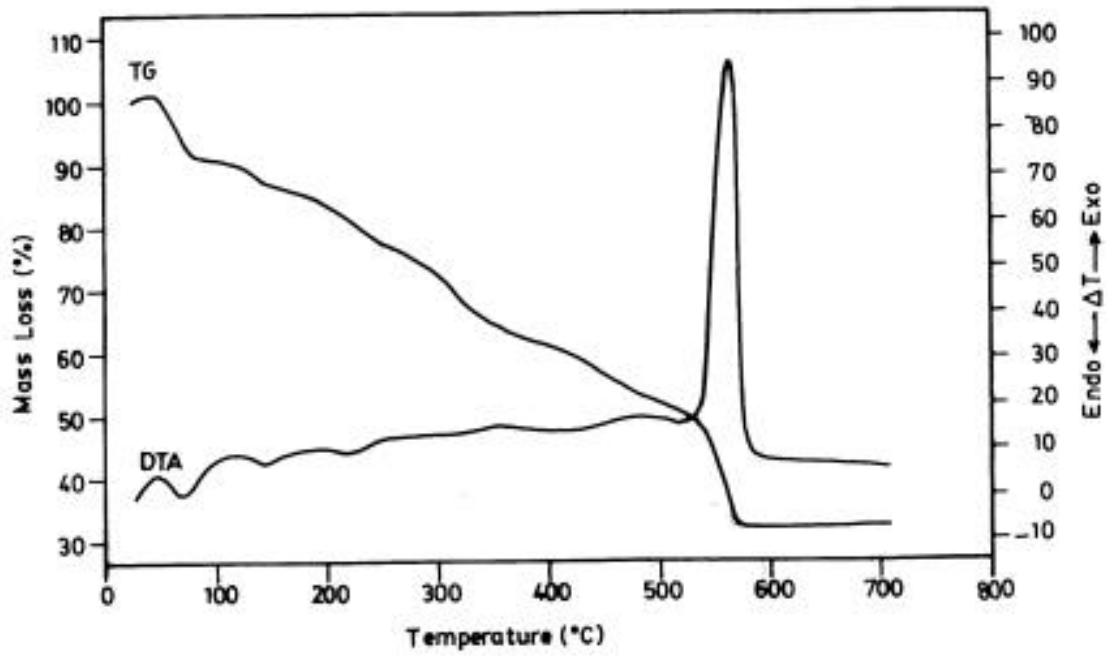

Figure 5. Simultaneous TG-DTA curves of $\left(\mathrm{N}_{2} \mathrm{H}_{5}\right)_{2} \mathrm{Ba}(\mathrm{dip})_{2} \cdot 4 \mathrm{H}_{2} \mathrm{O}$.

observed at $113^{\circ} \mathrm{C}$ is due to the loss of one molecule of hydrazine to form monohydrazinium calcium dipicolinate as an intermediate, which again loses hydrazine endothermically to form calcium hydrogendipicolinate as an intermediate. This intermediate undergoes a continuous exothermic decomposition with peak temperatures at 289,447 and $537^{\circ} \mathrm{C}$ into calcium dipicolinate, which is supported by TG. In the final step, the calcium dipicolinate intermediate decomposes exothermically at $593^{\circ} \mathrm{C}$ to produce calcium carbonate. 


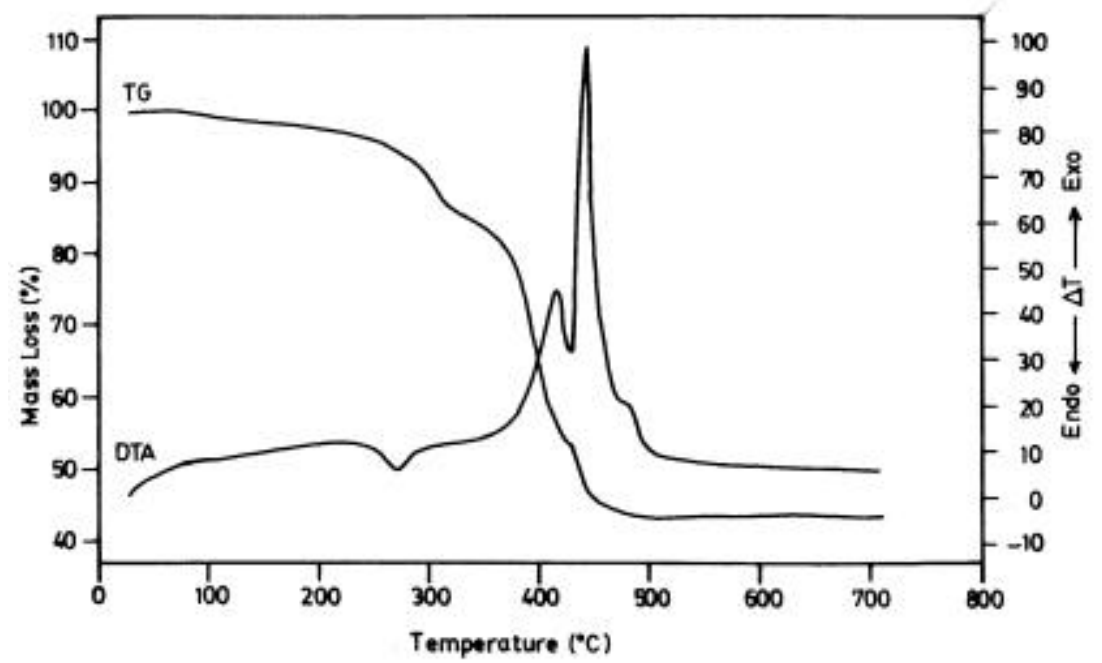

Figure 6. Simultaneous TG-DTA curves of $\mathrm{N}_{2} \mathrm{H}_{5} \mathrm{Bi}(\mathrm{dip})_{2} .3 \mathrm{H}_{2} \mathrm{O}$.

$3.3 \mathrm{~b} \quad\left(\mathrm{~N}_{2} \mathrm{H}_{5}\right)_{2} \mathrm{Sr}(\text { dip })_{2} .2 \mathrm{H}_{2} \mathrm{O}$ : This compound undergoes three stages of mass loss. The first stage that occurs in the range $85-195^{\circ} \mathrm{C}$ is attributed to the loss of two molecules of water. The corresponding DTA peak is observed as an endotherm at $190^{\circ} \mathrm{C}$. Such high temperature dehydration is in support of the presence of coordinated water molecules in the compound. The second stage mass loss also takes place endothermically at $270^{\circ} \mathrm{C}$ as shown by DTA. This mass loss is in accordance with the loss of two molecules of hydrazine to form strontium hydrogendipicolinate intermediate, which finally undergoes exothermic decomposition to give $\mathrm{SrCO}_{3}$. In DTA this is observed as an exothermic doublet with peak temperatures at 520 and $555^{\circ} \mathrm{C}$.

$3.3 \mathrm{c}\left(\mathrm{N}_{2} \mathrm{H}_{5}\right)_{2} \mathrm{Ba}(\mathrm{dip})_{2} .4 \mathrm{H}_{2} \mathrm{O}$ : The barium compound decomposes in five steps. The first weight loss $(8.50 \%)$ observed endothermically at $67^{\circ} \mathrm{C}$ can be attributed to the release of three water molecules (calculated $8.90 \%$ ). Such a low temperature endothermic dehydration indicates that the water molecules are not coordinated to the metal. In the second step the remaining water molecule is lost endothermically at $142^{\circ} \mathrm{C}$, suggesting that the water molecule is coordinated to the metal. The anhydrous compound then loses two molecules of hydrazine endothermically at $221^{\circ} \mathrm{C}$ to form barium hydrogendipicolinate as an intermediate. This intermediate then undergoes exothermic decomposition at 360 and $490^{\circ} \mathrm{C}$ into barium dipicolinate, which finally decomposes into barium carbonate in an exothermic $\left(565^{\circ} \mathrm{C}\right)$ fashion as in other cases.

$3.3 \mathrm{~d} \quad\left(\mathrm{~N}_{2} \mathrm{H}_{5}\right)_{2} \mathrm{~Pb}(\mathrm{dip})_{2} .3 \mathrm{H}_{2} \mathrm{O}$ : This compound also shows three clear steps of decomposition. In the first step, three molecules of water are lost endothermically at $220^{\circ} \mathrm{C}$. Such a high temperature of dehydration confirms the coordination of water molecules to the metal. In the second step, the anhydrous compound loses two molecules each of hydrazine and carbondioxide endothermically at $385^{\circ} \mathrm{C}$ to give lead picolinate as an intermediate. The formation of this intermediate is supported by a break around $30 \%$ 
in TG. In the last step, the lead picolinate decomposes sharply at $452^{\circ} \mathrm{C}$ (exothermic) with a shoulder at $496^{\circ} \mathrm{C}$ to give $\mathrm{PbCO}_{3}$.

3.3e $\mathrm{N}_{2} \mathrm{H}_{5} \mathrm{Bi}(\mathrm{dip})_{2} .3 \mathrm{H}_{2} \mathrm{O}$ : This monohydrazinium compound shows two steps of decomposition in accordance with DTA showing one endotherm and a exothermic doublet with a shoulder. The first endotherm at $270^{\circ} \mathrm{C}$ corresponds to the loss of one molecule of hydrazine and three molecules of water to form bismuth dipicolinate as an intermediate. Here also the high temperature dehydration confirms that the water molecules are coordinated to the metal. The bismuth dipicolinate then decomposes into bismuth oxycarbonate.This is seen as a exothermic doublet at 415 and $441^{\circ} \mathrm{C}$ with a shoulder at $479^{\circ} \mathrm{C}$ in DTA. Corresponding to this $\mathrm{TG}$ also shows a continuous decomposition, but with a break around $46.50 \%$. This may be probably due to the formation of bismuth oxalate, as an intermediate, which further decomposes to bismuth oxycarbonate. The theoretical mass loss for the formation of bismuth oxalate is $45.55 \%$, which coincides with the observed value of $46.50 \%$.

3.3f $\left(\mathrm{N}_{2} \mathrm{H}_{5}\right)_{3} \mathrm{Bi}(\mathrm{dip})_{3} \cdot 4 \mathrm{H}_{2} \mathrm{O}$ : The TG of this trihydrazinium compound shows three steps of decomposition. In the first step, all the four molecules of water are lost endothermically at $73^{\circ} \mathrm{C}$ suggesting the presence of water molecules as a lattice water. In the second step, three hydrazine molecules and one dipicolinate are lost endothermically in the range $105-300^{\circ} \mathrm{C}$ to give bismuth dipicolinate as an intermediate. The bismuth dipicolinate intermediate then decomposes as in the previous case.

Table 4. X-ray powder diffraction data ( $d$ spacings in $\AA$ and relative intensities in parentheses).

\begin{tabular}{|c|c|c|c|c|c|}
\hline \multicolumn{4}{|c|}{$\left(\mathrm{N}_{2} \mathrm{H}_{5}\right)_{2} \mathrm{M}(\operatorname{dip})_{2} \cdot n \mathrm{H}_{2} \mathrm{O}$} & \multirow{2}{*}{$\begin{array}{c}\mathrm{N}_{2} \mathrm{H}_{5} \mathrm{Bi} \\
(\operatorname{dip})_{2} \cdot 3 \mathrm{H}_{2} \mathrm{O}\end{array}$} & \multirow{2}{*}{$\begin{array}{l}\left(\mathrm{N}_{2} \mathrm{H}_{5}\right)_{3} \mathrm{Bi} \\
(\mathrm{dip})_{3} \cdot 4 \mathrm{H}_{2} \mathrm{O}\end{array}$} \\
\hline $\mathrm{M}=\mathrm{Ca}, n=0$ & $\mathrm{M}=\mathrm{Sr}, n=2$ & $\mathrm{M}=\mathrm{Ba}, n=4$ & $\mathrm{M}=\mathrm{Pb}, n=3$ & & \\
\hline $8 \cdot 26(54)$ & $6 \cdot 80(100)$ & $6 \cdot 06(68)$ & $6 \cdot 41(41)$ & $6 \cdot 80(92)$ & $8 \cdot 26(100)$ \\
\hline $6 \cdot 46(56)$ & $6 \cdot 23(62)$ & $5 \cdot 60(26)$ & $5.90(38)$ & $6 \cdot 15(100)$ & $6 \cdot 06(73)$ \\
\hline $5 \cdot 34(37)$ & $5 \cdot 71(46)$ & $5 \cdot 04(26)$ & $5 \cdot 34(66)$ & $5 \cdot 71(83)$ & $5 \cdot 15(46)$ \\
\hline $4 \cdot 37(40)$ & $5 \cdot 30(47)$ & $4 \cdot 44(31)$ & $3 \cdot 97(41)$ & $5 \cdot 37(73)$ & $4.87(42)$ \\
\hline $4 \cdot 06(43)$ & $4 \cdot 44(50)$ & $4 \cdot 21(76)$ & $3 \cdot 75(51)$ & $4.98(50)$ & $4 \cdot 57(39)$ \\
\hline $3 \cdot 62(37)$ & $4 \cdot 21(61)$ & $3 \cdot 95(32)$ & $3 \cdot 52(100)$ & $4 \cdot 64(48)$ & $4 \cdot 29(59)$ \\
\hline $3.73(100)$ & $4.00(65)$ & $3.59(46)$ & $3 \cdot 12(51)$ & $3.95(53)$ & $3.93(62)$ \\
\hline $3 \cdot 12(32)$ & $3 \cdot 78(64)$ & $3 \cdot 15(100)$ & $3 \cdot 00(49)$ & $3 \cdot 68(72)$ & $3 \cdot 60(48)$ \\
\hline $2 \cdot 82(37)$ & $3 \cdot 55(69)$ & $3.03(35)$ & $2.77(50)$ & $3 \cdot 53(78)$ & $3 \cdot 39(80)$ \\
\hline $2 \cdot 42(31)$ & $3 \cdot 39(88)$ & $2 \cdot 80(33)$ & $2 \cdot 54(41)$ & $3 \cdot 31(69)$ & $3 \cdot 18(45)$ \\
\hline \multirow[t]{10}{*}{$2 \cdot 15(29)$} & $3 \cdot 07(61)$ & $2 \cdot 53(71)$ & $2 \cdot 33(48)$ & $3 \cdot 18(73)$ & $2 \cdot 85(44)$ \\
\hline & $2 \cdot 87(52)$ & $2 \cdot 35(34)$ & & $2.99(46)$ & $2 \cdot 66(48)$ \\
\hline & $2 \cdot 78(54)$ & $2 \cdot 22(29)$ & & $2 \cdot 77(55)$ & $2 \cdot 38(49)$ \\
\hline & $2 \cdot 61(86)$ & $2 \cdot 16(44)$ & & $2 \cdot 67(53)$ & \\
\hline & $2 \cdot 43(55)$ & $2 \cdot 07(22)$ & & $2 \cdot 53(48)$ & \\
\hline & $2 \cdot 35(64)$ & $1.97(26)$ & & $2 \cdot 29(47)$ & \\
\hline & $2 \cdot 28(56)$ & $1 \cdot 81(18)$ & & $2 \cdot 13(68)$ & \\
\hline & $2 \cdot 17(59)$ & $1 \cdot 57(17)$ & & $2 \cdot 07(56)$ & \\
\hline & $2 \cdot 11(60)$ & & & $1.94(41)$ & \\
\hline & $1 \cdot 74(48)$ & & & $1.89(43)$ & \\
\hline
\end{tabular}




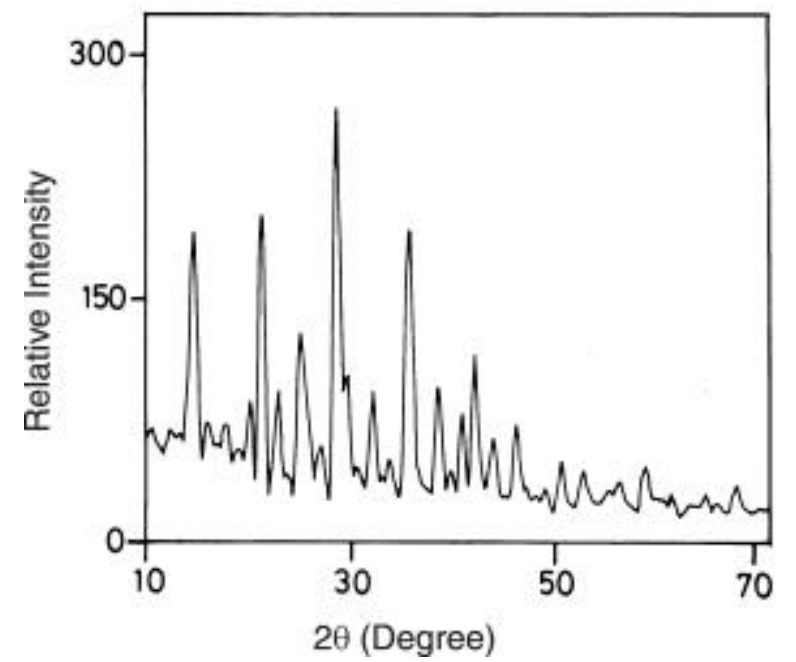

Figure 7. X-ray powder diffraction pattern of $\left(\mathrm{N}_{2} \mathrm{H}_{5}\right)_{2} \mathrm{Ba}(\operatorname{dip})_{2} \cdot 4 \mathrm{H}_{2} \mathrm{O}$.

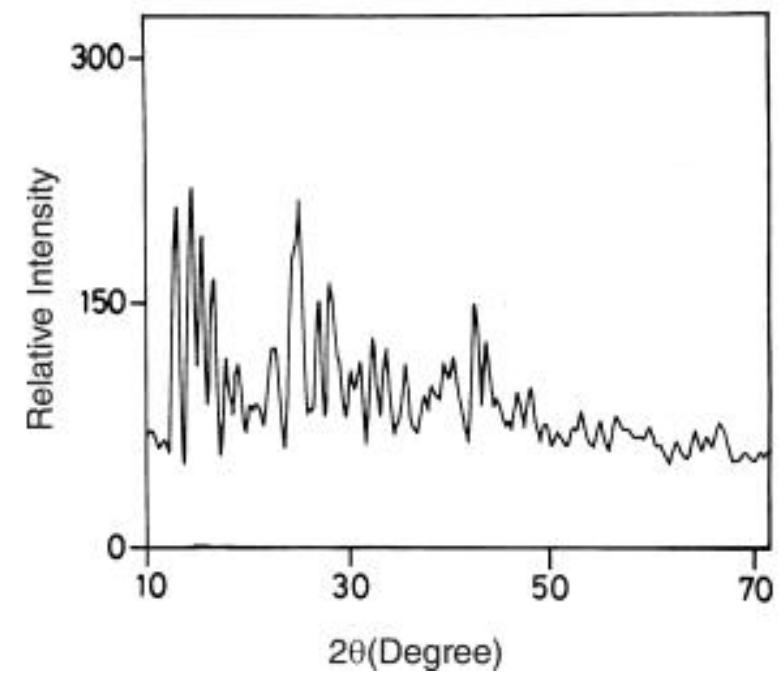

Figure 8. X-ray powder diffraction pattern of $\mathrm{N}_{2} \mathrm{H}_{5} \mathrm{Bi}(\operatorname{dip})_{2} \cdot 3 \mathrm{H}_{2} \mathrm{O}$.

\subsection{X-ray powder diffraction}

The X-ray diffraction patterns of these compounds differ from one another suggesting that the structures of the compounds are not same and the X-ray powder diffraction data of the complexes are summarised in table 4. The X-ray powder diffractograms of barium and monohydrazinium bismuth compounds are given in figures 7 and 8 respectively as references. 


\section{Conclusions}

New dipicolinate complexes of main group metals $(\mathrm{Ca}, \mathrm{Sr}, \mathrm{Ba}, \mathrm{Pb}$ and $\mathrm{Bi}$ ) with hydrazinium cation have been prepared and characterised. Attempt to prepare similar type of complexes with other main group metals such as $\mathrm{Mg}, \mathrm{Sn}$ and $\mathrm{Sb}$ was unsuccessful due to the formation of insoluble dipicolinates. Bismuth forms both $1: 2$ and $1: 3$ (metal: dipicolinic acid) complexes whereas other metals form only $1: 2$ complexes.

The physico-chemical studies suggest that in these complexes the metal ions are coordinated by tridentate dipicolinate dianion and some water molecules, and the hydrazinium ions are present only as charge compensating counter ions. Accordingly six, seven and eight coordination has been proposed for calcium, barium and strontium, respectively, and nine coordination for lead and bismuth complexes. Such a kind of higher coordination number has been reported for lead (ten) in lead nitrate semicarbazone $^{19}$ and for bismuth (eight and nine) in EDTA ${ }^{20}$ and DTPA ${ }^{20}$ complexes.In the present cases also the higher coordination number is not highly improbable due to the multidonor ability of the dipicolinate dianion.

Though these compounds show multiple steps of decomposition, all of them lose hydrazine endothermically $\left(>200^{\circ} \mathrm{C}\right)$, to give the respective metal hydrogendipicolinates. These intermediates further decompose with exothermic multiplets to give the corresponding metal carbonates except bismuth giving oxycarbonate as the end product. The compounds are not isomorphous, as evidenced from the X-ray powder diffraction data.

\section{References}

1. Brzyska W and Ozga W 1994 Thermochim. Acta 247324

2. Nathan L C, Zapien D C, Mooring A M, Doyle C A and Brown J A 1989 Polyhedron 8745

3. Zhou X Y and Kostic N M 1988 Inorg. Chem. 274402

4. Chessa G, Mirangoni G, Pitteri B, Bertolassi V, Gilli G and Ferreti V 1991 Inorg. Chim. Acta 185201

5. Nardin G, Randaccio L, Bononzo R P and Rizzarelli E 1980 J. Chem. Soc., Dalton Trans. 369

6. Sengupta S K, Shani S K and Kapoor R N 1983 Polyhedron 2317

7. Herring A M, Henling L, Labinger J A and Bercaw J E 1991 Inorg. Chem. 30851

8. Hoggard P E and Schmidtke H H 1973 Inorg. Chem. 121986

9. Laine P, Gourdon A and Launay J-P 1995 Inorg. Chem. 345129

10. Nathan L C, Zapien D C, Mooring A M, Doyle C A and Brown J A 1989 Polyhedron 8745

11. Albertsson J 1972 Acta Chem. Scand. 26985

12. Baracco L, Bombieri G, Degetto S, Forsellini E, Grazioni R and Marangoni 1974 Inorg. Nucl. Chem. Lett. 101045

13. Maragoni G, Dagetto S, Graziani R, Bombieri G and Forsellini E 1974 J. Inorg. Nucl. Chem. 341787

14. Govindarajan S, Patil K C, Poojary M D and Manohar H 1986 Inorg. Chim. Acta 120103

15. Govindarajan S, Patil K C, Manohar H and Werner P E 1986 J. Chem. Soc., Dalton Trans. 119

16. Govindarajan S and Patil K C 1982 Thermochim. Acta 55373

17. Gerry W J 1971 Coord. Chem. Rev. 781

18. Braibanti A, Dallavalle F, Pellinghelli M A and Laporati E 1968 Inorg. Chem. 71430

19. Aghabozorg H, Palenik R C and Palenik G J 1986 Inorg. Chim. Acta 111 L53

20. Summers S P, Abboud K A, Farrah S R and Palenik G J 1994 Inorg. Chem. 3388 